\title{
Effects of Bacterial Fermentation on the Biochemical Constituents and Antioxidant Potential of Fermented and Unfermented Soybeans Using Probiotic Bacillus subtilis (KCTC 13241)
}

\author{
Muhammad Waqas Ali ${ }^{1}$ (D), Il-Doo Kim ${ }^{2}$, Saqib Bilal ${ }^{1}$, Raheem Shahzad ${ }^{1}$, \\ Muhammad Tariq Saeed ${ }^{3}$, Bishnu Adhikari ${ }^{1}$, Rizwana Begum Syed Nabi ${ }^{1}$, Jeong Rae Kyo ${ }^{1}$ and \\ Dong-Hyun Shin ${ }^{1 \text {,* }}$ \\ 1 School of Applied Biosciences, Kyungpook National University, Daegu 41566, Korea; \\ waqasali3515@yahoo.com (M.W.A.); saqib043@yahoo.com (S.B.); raheemshehzad@ymail.com (R.S.); \\ bishnu.adhk@gmail.com (B.A.); ruhii.syed@gmail.com (R.B.S.N.); rhkddms1128@naver.com (J.R.K.) \\ 2 Institute of International Research \& Development, Kyungpook National University, Daegu 41566, Korea; \\ ildookim@hanmail.net \\ 3 Department of Agronomy, University of Agriculture Faisalabad, Faisalabad 38040, Pakistan; \\ mtsuaf@gmail.com \\ * Correspondence: dhshin@knu.ac.kr; Tel.: +82-53-950-5707
}

Received: 16 November 2017; Accepted: 6 December 2017; Published: 11 December 2017

\begin{abstract}
Fermented soybeans, cheonggukjang (CKJ), are considered to be more wholesome than soybeans in Korea. To select the best soybean cultivar for making functional CKJ, a comparison was made between the biological activities of four soybean cultivars in their unfermented soybean (UFS) and CKJ states. Changes in 1,1-diphenyl-2-picrylhydrazyl (DPPH) radical-scavenging activity, 2,2' azino-bis (3-ethylbenzothiazoline-6-sulphonic acid) (ABTS) assays, superoxide dismutase (SOD)-like activity, total phenolic compounds, total amino acids, and isoflavones were investigated. The levels of $\mathrm{DPPH}, \mathrm{ABTS}$, SOD-like activity, and total phenolic compounds increased in CKJ among all cultivars. The isoflavone aglycone and total amino acids showed the highest amount in CKJ prepared from soybean cultivar Aga 3. These results suggest that the improved antioxidant activity of CKJ in all cultivars might occur because of the higher levels of aglycones and total phenolic compounds achieved during fermentation. Moreover, CKJ prepared from soybean cultivar Aga 3 showed higher antioxidant activity than the other cultivars and so can be considered for the commercial production of functional foods in the future.
\end{abstract}

Keywords: soybean; isoflavones; phenolic contents; antioxidant activity; cheonggukjang

\section{Introduction}

Reactive oxygen species (ROS) and oxygen free radicals, such as superoxide anion radicals, hydroxyl radicals, peroxides, and singlet oxygen, are produced in the human body when antioxidative defence systems become imbalanced. These radicals cause lipid peroxidation, which is the main reason for the deterioration of food. ROS are also a source of cell and tissue damage, such as cancer, cirrhosis, osteoporosis, diabetes, and ageing, through oxidising biological molecules [1]. Internally and externally produced antioxidants such as catalase, glutathione peroxidase, superoxide dismutase, ascorbic acid, and polyphenols work as defences against ROS [2]. Internally produced antioxidants alone are not adequate for a human body to prevent damage from ROS, therefore it is essential to get additional antioxidants from external sources like food. 
Soybeans (Glycine max L.) have been a major food in Asian countries for thousands of years. They have high lipid and protein content and a balanced distribution of amino acids. They are also of vital importance due to containing physiologically active compounds that act as phytochemicals [3]. Soybeans are considered a rich source of many potent antioxidants, such as isoflavones, tocopherol, saponins, and phytic acids [4]. Soybeans contain different isoflavones and these isoflavones present in four different chemical forms: malonylglucosides (malonyldaidzin, malonylgenistin, and malonylglycitin), glucosides (daidzin, genistin, and glycitin), acetylglucosides (acetlyldaidzin, acetylgenistin, and acetylglycitin), and aglycones (daidzein, genistein, and glycitein); and have therapeutic roles against various lethal diseases such as cancer and cardiovascular disease caused by oxidative stress [5]. These functional compounds have high activity when soybeans are fermented using potential probiotics [6].

Microorganisms are seen as a source of antioxidant production in fermented foods, including tempeh produced by Rhizopus oligosporus in Indonesia [7]; Chinese douche produced by Aspergillus oryzae; Chinese sufu; Japanese miso produced by Saccharomyces rouxii; Japanese natto; and kanjang, doenjang, and cheonggukjang (CKJ) in Korea [8]. CKJ is a famous Korean fermented soybean that is consumed as a major food source [9]. Various studies have reported CKJ as being one of the best sources of protein, lipids, and hydrolyzed peptides, as well as being a health-promoting food [10]. It is also famous due to its fibrous texture, sticky and unique flavour, promising antioxidant, antigenotoxic, antimicrobial, anticancer, and antidiabetics activities, as well as its ability to control cholesterol levels in the body [11,12]. In addition, several studies have reported that the intake of fermented soybeans is related to a reduction in breast and prostate cancer rates in Asians [13].

On the basis of the aforementioned qualities of CKJ, this study aimed to identify and determine the best Korean soybean cultivar for producing cheonggukjang with superior phytochemical content and biological activity, using probiotic Bacillus subtilis (KCTC 13241) for the fermentation of the soybeans. The main focus of our research was CKJ prepared by the fermentation of soybeans at $42{ }^{\circ} \mathrm{C}$ with the microbial organism B. subtilis. For this purpose, four different soybean cultivars, Aga 3, Saedanbeck, Pungsannamul, and Daewon, were selected to evaluate the resulting CKJ for its phytochemical content, including isoflavones, total phenolic contents (TPC), and amino acid composition, as well as variation in the viability rates of cells in the CKJ. Additionally, the in vitro antioxidative activities of CKJ were investigated to assess their role in oxidative stress.

\section{Results and Discussion}

\subsection{Viable Cell Number and $p H$ of Unfermented Soybeans and Cheonggukjang}

The viable cell number and $\mathrm{pH}$ of $\mathrm{CKJ}$ prepared with four different cultivars during fermentation by B. subtilis (KCTC 13241) increased (Table 1). The viable cell numbers in UFS made with Daewon, Saedanbeck, Aga 3, and Pungsannamul were 4.85, 4.81, 5.18, and 5.08 (log CFU/g), and increased following fermentation to $10.21,10.11,10.46$, and 10.32, respectively. This change might be due to the fermentation period. In a previous study, it was reported that viable cell numbers markedly increased after fermentation [14], which is in strong agreement with our study. The $\mathrm{pH}$ of CKJ also increase into the range of 7.02-8.58 after $48 \mathrm{~h}$ fermentation. The increase in $\mathrm{pH}$ was a result of the breakdown of proteins into amino acids and the subsequent release of ammonia. These amino acids were utilised by the fermenting bacteria [14-16]. 
Table 1. Viable cell number and $\mathrm{pH}$ of unfermented soybeans and cheonggukjang fermented by Bacillus subtilis (KCTC 13241).

\begin{tabular}{|c|c|c|c|}
\hline Cultivars & Samples $^{1}$ & Viable Cell Numbers (log CFU/g) & $\mathrm{pH}$ \\
\hline \multirow{2}{*}{ Daewon } & UFS $^{2}$ & $4.85 \pm 0.72^{\mathrm{a}}$ & $5.87 \pm 0.18^{b}$ \\
\hline & $\mathrm{CKJ}^{3}$ & $10.21 \pm 0.84^{\mathrm{a}}$ & $7.79 \pm 0.55^{b}$ \\
\hline \multirow{2}{*}{ Saedanbeck } & UFS & $4.81 \pm 0.41^{\mathrm{a}}$ & $5.19 \pm 0.35^{c}$ \\
\hline & $\mathrm{CKJ}$ & $10.11 \pm 1.03^{\mathrm{a}}$ & $7.02 \pm 0.22^{c}$ \\
\hline \multirow{2}{*}{ Aga 3} & UFS & $5.18 \pm 0.80^{\mathrm{a}}$ & $6.26 \pm 0.20^{a}$ \\
\hline & $\mathrm{CKJ}$ & $10.46 \pm 1.21^{\mathrm{a}}$ & $8.58 \pm 0.28^{a}$ \\
\hline \multirow{2}{*}{ Pungsannamul } & UFS & $5.08 \pm 0.37^{\mathrm{a}}$ & $6.19 \pm 0.14^{\mathrm{a}}$ \\
\hline & $\mathrm{CKJ}$ & $10.32 \pm 0.36^{\mathrm{a}}$ & $8.33 \pm 0.12^{a}$ \\
\hline
\end{tabular}

${ }^{1}$ Values indicate the means of three replications $(n=3)$. Means with different lowercase letters $\left({ }^{\mathrm{a}}, \mathrm{b}\right.$, and $\left.{ }^{\mathrm{c}}\right)$ indicate significant differences between unfermented soybeans and cheonggukjang by Duncan's multiple range tests (DMRT) at the $95 \%$ confidence level. ${ }^{2}$ UFS: unfermented soybeans. ${ }^{3} \mathrm{CKJ}$ : cheonggukjang fermented at $42{ }^{\circ} \mathrm{C}$ for $48 \mathrm{~h}$.

\subsection{Antioxidant Activity of Unfermented Soybeans and Cheonggukjang}

The DPPH radical-scavenging assay, based on an electron-transfer reaction, is one of the most effective and widely-used assays for measuring the antioxidant activity of food and plant materials. In the presence of antioxidants, these free radicals form a colourless solution [17]. The DPPH scavenging capacity of samples is implied by the degree of reduction. The electron-donating activity of UFS and CKJ were tested in our study. Figure 1 represents the percentage of DPPH radical-scavenging activity in all samples. The DPPH percentage of UFS was in the range of $59.10-70.91 \%$ at $0 \mathrm{~h}$ fermentation, and increased to being in the range of $81.48-90.90 \%$ after $48 \mathrm{~h}$ fermentation. The antioxidant activity of CKJ was in the sequence Aga $3>$ Pungsannamul $>$ Daewon $>$ Saedanbeck according DPPH radical-scavenging assay results. After $48 \mathrm{~h}$ fermentation, these cultivars showed $19.54 \%, 18.38 \%$, $16.11 \%$, and $22.38 \%$ higher DPPH activity, respectively. The cultivar Aga 3 exhibited $71.35 \%$ DPPH activity at $0 \mathrm{~h}$ fermentation, and after $48 \mathrm{~h}$ fermentation it rose to $90.90 \%$. The next highest cultivar was Pungsannamul, which and showed $70.91 \%$ DPPH activity at $0 \mathrm{~h}$ fermentation and $89.29 \%$ at $48 \mathrm{~h}$. The lowest DPPH percentage was measured in Saedanbeck with DPPH activity values of $59.10 \%$ and $81.48 \%$ for UFS and CKJ, respectively. These results exhibited higher antioxidant activities than those reported by Cheongja [18], and this may be due to different cultivars or microorganisms. Yee et al. [10] suggested that CKJ and its constituents show significant antioxidant activity. The rise in the radical-scavenging activity after fermentation depends on the isoflavone and total phenolic contents produced during fermentation by the potential probiotic B. subtilis CS90 [14].

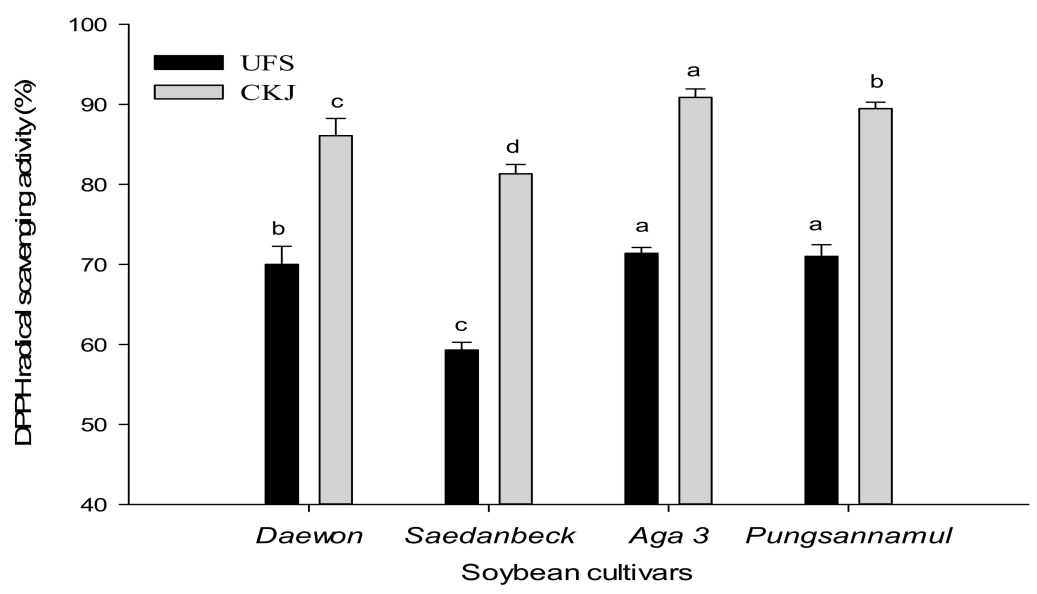

Figure 1. Changes in DPPH radical-scavenging activity between UFS and CKJ fermented by Bacillus subtilis (KCTC 13241) in different soybean cultivars. All values are means of three independent experiments. Means with different lowercase letters ( $a, b, c$, and d) represent significant differences among cultivars by Duncan's multiple range tests (DMRT) $(p<0.05)$. 
ABTS radical-scavenging activity has been mostly used as an assessment of the antioxidant activity of food [19]. The antioxidant activity of extracts containing hydrophilic compounds is measured by ABTS assay. A stable ABTS radical, which has blue-green chromophore absorption, is produced by the oxidation of ABTS with potassium persulfate. The ABTS assay is based on the discoloration of the ABTS assay solution by measuring the reduction in absorbance at $734 \mathrm{~nm}$ [20]. The change in ABTS radical-scavenging activity for UFS and CKJ is shown in Figure 2. All cultivars made from CKJ had a higher percentage of ABTS radical-scavenging activity than UFS. These percentages ranged from 70.30 to $79.49 \%$ in UFS and 83.36 to $93.22 \%$ in CKJ, and cultivars were ranked: Aga $3>$ Pungsannamul $>$ Daewon > Saedanbeck. The ABTS radical-scavenging activity in CKJ increased by 1.21-, 1.19-, 1.18-, and 1.19-fold in Aga 3, Pungsannamul, Daewon, and Saedanbeck respectively. However, like in the DPPH assay, CKJ prepared from Aga 3 cultivar showed significantly $(p<0.05)$ greater ABTS radical-scavenging activity $(93.22 \%)$ compared to those of the other cultivars. This change might be due to fermentation. Our results are similar to a previous study in which a Tae-Kwang soybean cultivar was reported and inoculated with B. subtilis W42 and B. amyloliquefaciens [21]. Additionally, another study reported that levels of ABTS radical activity in CKJ prepared from Seoritae and Seormoktae increased from $70.81 \%$ and $64.87 \%$ at $0 \mathrm{~h}$ fermentation, to $91.06 \%$ and $81.12 \%$ at $48 \mathrm{~h}$ fermentation, respectively [22]. These results are strongly supportive of our findings.

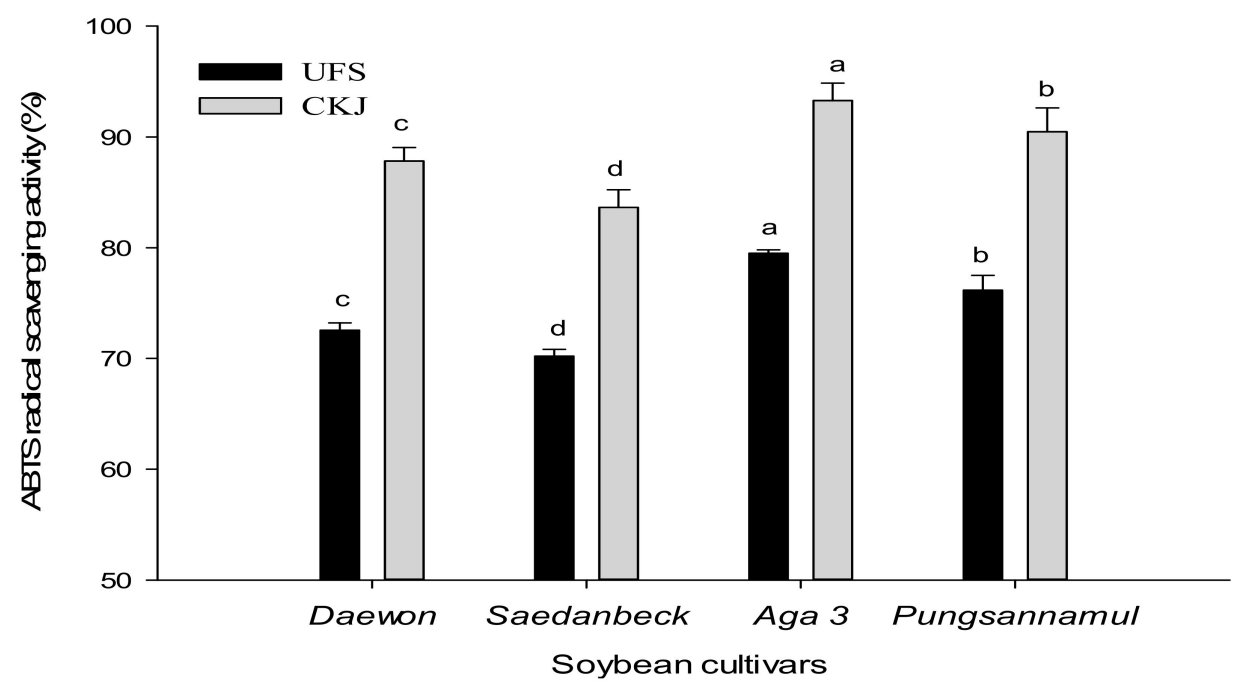

Figure 2. Changes in ABTS radical-scavenging activity between UFS and CKJ fermented by Bacillus subtilis (KCTC 13241) in different soybean cultivars. All values are means of three independent experiments. Means with different lowercase letters (a, b, c, and d) represent significant differences among cultivars by Duncan's multiple range tests (DMRT) $(p<0.05)$.

Organic low molecular weight substances have SOD-like activity, including anti-aging properties and antioxidant effects. SOD-like activity is a natural antioxidant that removes active oxygen and maintains superoxide radicals [16]. The SOD-like activity of UFS was in the range of 20.87-26.76\% and in CKJ its range was 28.20-36.90\% (Figure 3). CKJ prepared from Aga 3 exhibited the highest statistically significant $(p<0.05)$ SOD activity $(36.90 \%)$ at $48 \mathrm{~h}$ fermentation and its activity in an UFS state was $26.76 \%$, while CKJ of the Saedanbeck variety exhibited the lowest $(28.20 \%)$ activity. Figure 3 shows that the SOD-like activities of UFS are increased in CKJ. A previous study reported that CKJ prepared from the Taekwang soybean cultivar showed 10\% SOD-like activity at $1000 \mathrm{ppm}$ in a methanol extract and $17.50 \%$ SOD-like activity at $1000 \mathrm{ppm}$ in a water extract [23]. In our study, we found that the SOD activities of our cultivars were higher than in the aforementioned reports. The SOD-like activity of CKJ prepared from the Cheongja soybean cultivar was reported at around $31.54 \%$, which is slightly higher than the results of our least-expressed cultivar, Saedanbeck [24]. We found that antioxidant 
activities, such as DPPH, ABTS, and SOD-like activity were also influenced by solvent extraction and bacterial strains for fermentation purposes. Additionally, the antioxidant activities might have been affected by the presence of either lower or higher levels of specific agents in the extracts such as isoflavone or phenolic contents.



Figure 3. Changes in SOD-like activity between UFS and CKJ fermented by Bacillus subtilis (KCTC 13241) in different soybean cultivars. All values are means of three independent experiments. Means with different lowercase letters ( $a, b, c$, and d) represent significant differences among cultivars by Duncan's multiple range tests (DMRT) $(p<0.05)$.

\subsection{Total Phenolic Contents of Unfermented Soybeans and Cheonggukjang}

Phenolic compounds are secondary metabolites that are present in plants and have beneficial activities. They may scavenge free radicals based on their electron donor ability. They are important in the food industry due to their lipid peroxidation-reducing ability [25]. Total phenolic content was identified in the extracts of UFS and CKJ as shown in Figure 4. Significant $(p<0.05)$ differences were identified between different cultivars and between UFS and CKJ. Total phenolic content predominantly increased in CKJ during $48 \mathrm{~h}$ of fermentation when compared to UFS. Moreover, among the four cultivars, CKJ prepared from Aga 3 showed the highest (11.51) value of total phenolic content. The total phenolic contents for both UFS and CKJ were in the following order: Aga $3>$ Pungsannamul > Daewon $>$ Saedanbeck with values of 4.29, 3.78, 3.49, and 2.82 for UFS, and 11.51, 8.84, 7.49, and 6.71 for CKJ, respectively. These findings were comparable to previously-reported results on unfermented soybeans and cheonggukjang. A previous study reported that total phenolic content increased during soybean fermentation of natto into cheonggukjang [14]. Shin et al. [26] also reported that the total phenolic contents of cheonggukjang prepared with brown soybeans increased when the probiotic Bacillus subtilis used. This study indicated that B. subtilis (KCTC 13241) has strong potential for the biotransformation of soybean biopolymers into beneficial polyphenols during fermentation. CKJ prepared from $\mathrm{Aga} 3$ was detected to be prominent in having a high level of phenolic content. CKJ of Aga 3 was also noted in exhibiting a high range of antioxidant activities. The results indicate that the presence of high levels of isoflavones might responsible for its influential role as an antioxidant. 


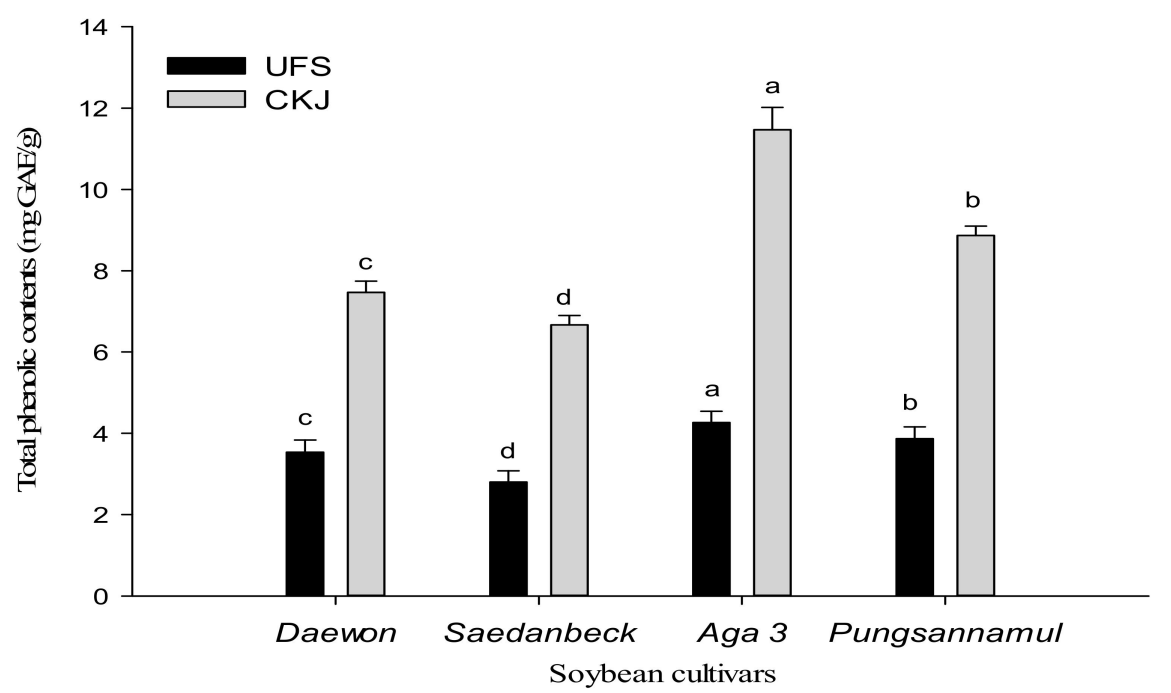

Figure 4. Changes in total phenolic contents (TPC) between UFS and CKJ fermented by Bacillus subtilis (KCTC 13241) in different soybean cultivars. All values are means of three independent experiments. Means with different lowercase letters $(a, b, c$, and $d$ ) represent significant differences among cultivars by Duncan's multiple range tests (DMRT) $(p<0.05)$.

\subsection{Isoflavone Composition of Unfermented Soybeans and Cheonggukjang}

Isoflavones are flavonoids present in soybean cultivars and are classified as phytoestrogens since their structures resemble that of estrogen and they have a weak affinity for the estrogen receptor [27]. In the current study, we analysed the effects of the bacterial strain B. subtilis (KCTC 13241) on the isoflavone composition of soybean cultivars. The isoflavone composition of four different soybean cultivars in UFS and CKJ states is listed in Table 2. Glycoside isoflavones, including daidzin, genistin, and glycitin, decreased in concentration in CKJ when compared to UFS, and aglycone isoflavones such as daidzein, glycitein, and genistein, significantly $(p<0.05)$ increased in CKJ. The concentration of these isoflavones was also different among different cultivars. Aga 3 showed a remarkable difference compared to cultivars; it had $1078.50 \mu \mathrm{g} / \mathrm{g}$ total isoflavone concentration in its UFS state and this decreased in its CKJ state to $785.99 \mu \mathrm{g} / \mathrm{g}$. Saedanbeck had the lowest concentration of total isoflavones among all cultivars.

The composition of these isoflavones depends upon the processing techniques used during fermentation, the microorganisms used, and the soybean cultivars used. Previous studies showed that the values of isoflavones in soybean foods, such as douche, cheonggukjang, and tofu, become low depending on the processing technique useds $[14,28]$. Cho et al. [14], reported that the total isoflavone composition in CKJ decreased by around $64 \%$, from $2923.21 \mu \mathrm{g} / \mathrm{g}$ to $1051.59 \mu \mathrm{g} / \mathrm{g}$, after $60 \mathrm{~h}$ of fermentation. In another study, the total isoflavone content decreased from $1055 \mu \mathrm{g} / \mathrm{g}$ in UFS $(0 \mathrm{~h}$ fermentation) to $870 \mu \mathrm{g} / \mathrm{g}$ ( $36 \mathrm{~h}$ fermentation) during fermentation by B. subtilis [29]. In our study, the total isoflavone content decreased by about $222.59,160.90,161.72$, and $292.51 \mu \mathrm{g} / \mathrm{g}$, after $48 \mathrm{~h}$ of fermentation of Daewon, Saedanbeck, Aga 3, and Pungsannamul, respectively.

Generally, isoflavones in soybean cultivars are present in the form of glycoside and are changed into aglycones during fermentation by microorganism activity [14,30]. Another study showed that aglycone isoflavones, such as daidzein, glycitein, and genistein, increased and glycoside isoflavones decreased in cheonggukjang as fermentation time increased [22]. It stated that the total isoflavones in food made under normal cooking conditions was not reduced, whereas food made under high-temperature conditions resulted in an increase the level of aglycones and a decrease in total isoflavone content [26]. In our study, we prepared UFS and CKJ by cooking the soybeans at $121^{\circ} \mathrm{C}$ for $30 \mathrm{~min}$ followed by $0 \mathrm{~h}$ and $48 \mathrm{~h}$ fermentation respectively. We found that $B$. subtilis (KCTC 13241) fermentation had the effect of increasing the aglycone content and decreasing the glycoside content. 
These results also demonstrated that isoflavone composition and concentration in soybean foods varies depending on the soybean variety, addition of microorganisms, cooking conditions, and fermentation duration.

Table 2. Changes in isoflavone contents between unfermented soybeans and cheonggukjang fermented by Bacillus subtilis (KCTC 13241) in different soybean cultivars.

\begin{tabular}{cccccc}
\hline \multirow{2}{*}{ Isoflavone $\mu \mathrm{g} / \mathrm{g}$} & \multirow{2}{*}{ Sample $^{\mathbf{2}}$} & \multicolumn{4}{c}{ Soybean Cultivars } \\
\cline { 3 - 5 } & & Daewon & Saedanbeck & Aga 3 & Pungsannamul \\
\hline \multirow{2}{*}{ Daidzin } & UFS $^{2}$ & $145.60 \pm 6.20^{\mathrm{c}}$ & $126.54 \pm 4.11^{\mathrm{d}}$ & $347.04 \pm 2.41^{\mathrm{a}}$ & $236.39 \pm 2.50^{\mathrm{b}}$ \\
& CKJ $^{3}$ & $47.70 \pm 5.36^{\mathrm{c}}$ & $26.84 \pm 1.91^{\mathrm{d}}$ & $162.05 \pm 1.12^{\mathrm{a}}$ & $130.68 \pm 4.37^{\mathrm{b}}$ \\
\hline \multirow{2}{*}{ Genistin } & UFS & $163.01 \pm 3.19^{\mathrm{c}}$ & $145.01 \pm 2.76^{\mathrm{d}}$ & $424.25 \pm 4.35^{\mathrm{a}}$ & $262.71 \pm 4.12^{\mathrm{b}}$ \\
& CKJ & $55.12 \pm 4.11^{\mathrm{c}}$ & $43.34 \pm 4.03^{\mathrm{d}}$ & $244.73 \pm 2.59^{\mathrm{a}}$ & $155.66 \pm 3.46^{\mathrm{b}}$ \\
\hline \multirow{2}{*}{ Glycitin } & UFS & $17.39 \pm 2.24^{\mathrm{c}}$ & $10.91 \pm 1.20^{\mathrm{d}}$ & $93.85 \pm 2.00^{\mathrm{a}}$ & $55.79 \pm 2.22^{\mathrm{b}}$ \\
& CKJ & $3.18 \pm 0.90^{\mathrm{c}}$ & $1.96 \pm 0.39^{\mathrm{d}}$ & $30.42 \pm 2.50^{\mathrm{a}}$ & $15.87 \pm 1.97^{\mathrm{b}}$ \\
\hline \multirow{2}{*}{ Daidzein } & UFS & $66.48 \pm 2.59^{\mathrm{c}}$ & $34.82 \pm 3.43^{\mathrm{d}}$ & $119.45 \pm 3.75^{\mathrm{a}}$ & $88.60 \pm 0.70^{\mathrm{b}}$ \\
& CKJ & $85.50 \pm 1.42^{\mathrm{c}}$ & $65.81 \pm 2.58^{\mathrm{d}}$ & $213.91 \pm 4.17^{\mathrm{a}}$ & $101.87 \pm 2.36^{\mathrm{b}}$ \\
\hline \multirow{2}{*}{ Glycitein } & UFS & $40.35 \pm 1.14^{\mathrm{c}}$ & $30.34 \pm 2.97^{\mathrm{d}}$ & $91.48 \pm 1.94^{\mathrm{a}}$ & $74.68 \pm 2.39^{\mathrm{b}}$ \\
& CKJ & $75.26 \pm 3.74^{\mathrm{c}}$ & $46.04 \pm 2.49^{\mathrm{d}}$ & $110.38 \pm 2.45^{\mathrm{a}}$ & $88.04 \pm 3.87^{\mathrm{b}}$ \\
\hline \multirow{2}{*}{ Genistein } & UFS & $3.18 \pm 0.31^{\mathrm{a}}$ & $1.32 \pm 0.48^{\mathrm{b}}$ & $2.43 \pm 0.45^{\mathrm{a}} \mathrm{b}$ & $3.17 \pm 0.89^{\mathrm{a}}$ \\
& CKJ & $7.64 \pm 0.05^{\mathrm{b}}$ & $4.16 \pm 0.69^{\mathrm{c}}$ & $24.50 \pm 1.53^{\mathrm{a}}$ & $8.63 \pm 0.70^{\mathrm{b}}$ \\
\hline \multirow{2}{*}{ Total isoflavones } & UFS & $436.00 \pm 0.54^{\mathrm{c}}$ & $348.94 \pm 0.36^{\mathrm{d}}$ & $1078.50 \pm 1.12^{\mathrm{a}}$ & $721.34 \pm 0.65^{\mathrm{b}}$ \\
& CKJ & $274.40 \pm 0.23^{\mathrm{c}}$ & $188.15 \pm 0.43^{\mathrm{d}}$ & $785.54 \pm 0.87^{\mathrm{a}}$ & $500.76 \pm 0.87^{\mathrm{b}}$ \\
\hline \multirow{2}{*}{ Valliny }
\end{tabular}

${ }^{1}$ Values indicate the means of three replications $(n=3)$. Means with different lowercase letters $\left({ }^{\mathrm{a}},{ }^{\mathrm{b}},{ }^{\mathrm{c}}\right.$, and $\left.{ }^{\mathrm{d}}\right)$ indicate significant differences between the unfermented soybeans and cheonggukjang by Duncan's multiple range tests (DMRT) at the $95 \%$ confidence level. ${ }^{2}$ UFS, unfermented soybean. ${ }^{3} \mathrm{CKJ}$, cheonggukjang fermented at $42{ }^{\circ} \mathrm{C}$ for $48 \mathrm{~h}$.

\subsection{Free Amino Acid Composition}

Twenty amino acids, including aspartic acid (Asp), threonine (Thr), serine (Ser), glutamic acid (Glu), $\alpha$-amino adipic acid (Aaa), glycine (Gly), alanine (Ala), citrulline (Cit), $\alpha$-amino- $n$-butyric acid (Aba), valine (Val), methionine (Met), cystathionine (Cys), isoleucine (Iso), leucine (Leu), tyrosine (Tyr), phenylalanine (Phe), $\beta$-alanine (Bal), $\beta$-amino isobutyric acid (Bam), $\gamma$-amino- $n$-butyric acid (Gaba), and ethanol amine (Eth), were analyzed in UFS and CKJ as shown in Table 3. Most of the amino acids, such as Asp, Thr, Glu, Gly, Ala, Val, Met, Cys, Iso, Leu, Tyr, Phe, Bal, Bam, and Eth, were identified at higher levels in CKJ among all cultivars than in UFS, while Cit showed higher values in UFS. The value of Ser in CKJ decreased in Aga 3 and Pungsannamul and increased in Daewon and Saedanbeck.

Gaba, naturally present in soybeans, was detected in all cultivars. It showed higher values in CKJ than in UFS among all cultivars, and Daewon had the highest value in CKJ. Gaba is produced in soybean foods by the decarboxylation of L-Glu, which is catalysed by glutamic decarboxylase [31]. Gaba has physiological roles, such as regulating cardiovascular functions and controlling blood pressure. However, Ser, Aaa, and Aba levels were low in all cultivars in both CKJ and UFS. Thr boosts the immune system and promotes the growth of thymus glands [32]. Leu helps in regulating oxidative glucose utilisation by skeletal muscles and also facilitates bone and skin wound healing by modulating enkephalins $[33,34]$.

Asp, Glu, and Ala play important roles in human health: Ala maintains glucose and nitrogen balance through the glucose-alanine cycle in the human body, Asp is beneficial in higher plants and acts as a precursor for the synthesis of several amino acids, and Glu is used for the treatment of various neurological disorders and is also famous for boosting the taste of food [35,36].

Overall, the value of amino acids in CKJ was higher than in UFS and a significant increase in amino acid levels was seen in CKJ after $48 \mathrm{~h}$ fermentation. Choi et al. [24] reported that the concentration of amino acids was higher in initial fermentation in cheonggukjang prepared from germinated soybeans. A previous study also showed that protein content decreased over the fermentation time $24-48 \mathrm{~h}$ 
in cheonggukjang made using Bacillus licheniformis. Amino acids such as Gly, Lys, and Glu can positively affect the quality of cheonggukjang, and Tyr and Phe are responsible for the savoury taste of cheonggukjang [37]. Aga 3 and Pungsannamul were identified as the best cultivars when we considered total free amino acid levels and these cultivars can be recommended for use in the production of the best CKJ.

Table 3. Analysis of free amino acid composition in unfermented soybean and cheonggukjang fermented by Bacillus subtilis (KCTC 13241) in different soybean cultivars.

\begin{tabular}{|c|c|c|c|c|c|}
\hline Amino Acids $\mu \mathrm{g} / \mathrm{g}$ & Sample $^{1}$ & Daewon & Saedanbeck & Aga 3 & Pungsannamul \\
\hline \multirow{2}{*}{ aspartic acid } & $\mathrm{UFS}^{2}$ & $99.38 \pm 2.20^{\mathrm{b}}$ & $43.39 \pm 1.14^{\mathrm{d}}$ & $138.33 \pm 1.96^{\mathrm{a}}$ & $56.52 \pm 0.22^{c}$ \\
\hline & $\mathrm{CKJ}^{3}$ & $443.95 \pm 2.15^{\mathrm{a}}$ & $368.56 \pm 1.42^{b}$ & $288.69 \pm 1.50^{d}$ & $320.98 \pm 1.65^{c}$ \\
\hline \multirow{2}{*}{ threonine } & UFS & $47.95 \pm 2.68^{b}$ & $5.20 \pm 0.36^{\mathrm{d}}$ & $79.22 \pm 1.33^{\mathrm{a}}$ & $39.38 \pm 0.57^{c}$ \\
\hline & $\mathrm{CKJ}$ & $171.72 \pm 2.09^{a}$ & $139.46 \pm 1.65^{c}$ & $143.79 \pm 2.12^{b}$ & $111.39 \pm 1.55^{\mathrm{d}}$ \\
\hline \multirow{2}{*}{ serine } & UFS & $26.69 \pm 1.30^{b}$ & $1.13 \pm 0.83^{\mathrm{d}}$ & $52.40 \pm 1.28^{a}$ & $15.98 \pm 3.42^{c}$ \\
\hline & $\mathrm{CKJ}$ & $44.99 \pm 1.29^{\mathrm{a}}$ & $13.90 \pm 1.47^{\mathrm{b}}$ & $13.32 \pm 0.53^{b}$ & $6.73 \pm 0.60^{c}$ \\
\hline \multirow{2}{*}{ glutamic acid } & UFS & $531.55 \pm 3.64^{b}$ & $381.82 \pm 2.97^{c}$ & $603.74 \pm 1.27^{\mathrm{a}}$ & $348.73 \pm 1.17^{\mathrm{d}}$ \\
\hline & $\mathrm{CKJ}$ & $1028.83 \pm 2.19^{a}$ & $975.96 \pm 0.78^{b}$ & $619.80 \pm 2.31^{c}$ & $430.90 \pm 0.84^{\mathrm{d}}$ \\
\hline \multirow{2}{*}{$\alpha$-amino adipic acid } & UFS & $96.99 \pm 4.46^{b}$ & $267.05 \pm 0.53^{a}$ & $54.41 \pm 0.97^{\mathrm{c}}$ & $55.32 \pm 1.58^{c}$ \\
\hline & $\mathrm{CKJ}$ & $106.79 \pm 0.76^{\mathrm{b}}$ & $115.53 \pm 1.56^{\mathrm{a}}$ & $39.16 \pm 2.41^{d}$ & $92.93 \pm 3.26^{c}$ \\
\hline \multirow{2}{*}{ glycine } & UFS & $176.04 \pm 1.03^{b}$ & $41.48 \pm 1.00^{\mathrm{d}}$ & $193.33 \pm 1.69^{a}$ & $116.88 \pm 3.03^{c}$ \\
\hline & $\mathrm{CKJ}$ & $291.14 \pm 2.20^{\mathrm{a}}$ & $218.58 \pm 1.04^{b}$ & $214.41 \pm 0.52^{\mathrm{c}}$ & $204.40 \pm 2.71^{\mathrm{d}}$ \\
\hline \multirow{2}{*}{ alanine } & UFS & $580.17 \pm 1.45^{\mathrm{a}}$ & $73.53 \pm 0.50^{d}$ & $420.89 \pm 2.99^{b}$ & $234.57 \pm 1.00^{c}$ \\
\hline & $\mathrm{CKJ}$ & $1017.40 \pm 2.25^{\mathrm{a}}$ & $544.99 \pm 1.23^{b}$ & $542.55 \pm 1.02^{\mathrm{c}}$ & $392.15 \pm 1.40^{\mathrm{d}}$ \\
\hline \multirow{2}{*}{ citrulline } & UFS & $221.09 \pm 3.43^{c}$ & $760.79 \pm 1.53^{a}$ & $365.01 \pm 0.64^{b}$ & $219.57 \pm 2.79^{d}$ \\
\hline & $\mathrm{CKJ}$ & $\mathrm{ND}^{\mathrm{c}}$ & $291.41 \pm 0.69^{\mathrm{a}}$ & $\mathrm{ND}^{\mathrm{c}}$ & $158.76 \pm 1.83^{b}$ \\
\hline \multirow{2}{*}{$\alpha$-amino- $n$-butyric acid } & UFS & $20.87 \pm 1.24^{\mathrm{a}}$ & $\mathrm{ND}^{\mathrm{c}}$ & $18.84 \pm 1.27^{\mathrm{b}}$ & $\mathrm{ND}^{\mathrm{c}}$ \\
\hline & $\mathrm{CKJ}$ & $12.50 \pm 0.55^{\mathrm{a}}$ & $10.98 \pm 2.20^{a, b}$ & $9.92 \pm 0.01^{b}$ & $10.55 \pm 1.06^{\mathrm{a}, \mathrm{b}}$ \\
\hline \multirow[b]{2}{*}{ valine } & UFS & $39.09 \pm 3.51^{\mathrm{c}}$ & $39.58 \pm 1.01^{\mathrm{c}}$ & $85.02 \pm 1.34^{\mathrm{a}}$ & $46.17 \pm 0.47^{\mathrm{b}}$ \\
\hline & $\mathrm{CKJ}$ & $133.26 \pm 1.18^{b}$ & $103.16 \pm 0.82^{c}$ & $148.05 \pm 1.19^{a}$ & $104.93 \pm 1.17^{c}$ \\
\hline \multirow{2}{*}{ methionine } & UFS & $28.18 \pm 3.54^{a}$ & $\mathrm{ND}^{\mathrm{c}}$ & $28.95 \pm 2.58^{a}$ & $24.45 \pm 0.51^{b}$ \\
\hline & $\mathrm{CKJ}$ & $102.36 \pm 2.52^{\mathrm{a}}$ & $76.07 \pm 1.87^{b}$ & $77.29 \pm 0.83^{b}$ & $68.69 \pm 1.26^{c}$ \\
\hline \multirow{2}{*}{ cystathionine } & UFS & $15.95 \pm 1.56^{\mathrm{a}}$ & $\mathrm{ND}^{\mathrm{c}}$ & $11.65 \pm 1.99^{b}$ & $14.71 \pm 2.26^{\mathrm{a}, \mathrm{b}}$ \\
\hline & $\mathrm{CKJ}$ & $16.83 \pm 1.86^{\mathrm{a}}$ & $14.16 \pm 2.55^{\mathrm{a}, \mathrm{b}}$ & $12.14 \pm 0.82^{b}$ & $15.02 \pm 1.46^{\mathrm{a}, \mathrm{b}}$ \\
\hline \multirow{2}{*}{ isoleucine } & UFS & $17.37 \pm 1.93^{\mathrm{d}}$ & $30.35 \pm 0.72^{b}$ & $42.78 \pm 0.59^{a}$ & $26.82 \pm 2.51^{c}$ \\
\hline & $\mathrm{CKJ}$ & $99.57 \pm 1.59^{b}$ & $75.96 \pm 1.67^{c}$ & $104.57 \pm 2.91^{a}$ & $73.67 \pm 0.37^{d}$ \\
\hline \multirow{2}{*}{ leucine } & UFS & $23.71 \pm 3.67^{c}$ & $4.33 \pm 0.80^{\mathrm{d}}$ & $82.42 \pm 2.57^{\mathrm{a}}$ & $39.60 \pm 0.50^{b}$ \\
\hline & $\mathrm{CKJ}$ & $195.29 \pm 2.46^{\mathrm{b}}$ & $142.13 \pm 1.87^{\mathrm{d}}$ & $225.25 \pm 0.75^{\mathrm{a}}$ & $152.81 \pm 1.59^{c}$ \\
\hline \multirow{2}{*}{ tyrosine } & UFS & $88.21 \pm 2.47^{b}$ & $56.87 \pm 0.66^{\mathrm{d}}$ & $136.28 \pm 1.45^{\mathrm{a}}$ & $76.58 \pm 1.22^{c}$ \\
\hline & $\mathrm{CKJ}$ & $170.89 \pm 3.89^{c}$ & $172.50 \pm 1.87^{\mathrm{b}}$ & $204.54 \pm 1.00^{\mathrm{a}}$ & $204.18 \pm 0.33^{a}$ \\
\hline \multirow{2}{*}{ phenylalanine } & UFS & $43.11 \pm 1.38^{\mathrm{d}}$ & $47.47 \pm 1.14^{\mathrm{c}}$ & $119.95 \pm 2.27^{a}$ & $80.77 \pm 0.97^{b}$ \\
\hline & $\mathrm{CKJ}$ & $184.06 \pm 1.73^{\mathrm{d}}$ & $189.72 \pm 0.86^{c}$ & $224.30 \pm 1.12^{b}$ & $235.76 \pm 1.58^{a}$ \\
\hline \multirow{2}{*}{$\beta$-alanine } & UFS & $126.44 \pm 2.22^{a}$ & $35.32 \pm 0.57^{c}$ & $43.78 \pm 1.05^{b}$ & $43.44 \pm 1.85^{b}$ \\
\hline & $\mathrm{CKJ}$ & $161.16 \pm 1.00^{\mathrm{a}}$ & $105.92 \pm 2.47^{b}$ & $60.75 \pm 1.81^{\mathrm{d}}$ & $101.36 \pm 2.13^{c}$ \\
\hline \multirow{2}{*}{$\begin{array}{c}\beta \text {-amino isobutyric } \\
\text { acid }\end{array}$} & UFS & $30.80 \pm 2.03^{c}$ & $46.71 \pm 1.89^{\mathrm{a}}$ & $21.88 \pm 1.73^{\mathrm{d}}$ & $39.06 \pm 0.73^{b}$ \\
\hline & $\mathrm{CKJ}$ & $56.61 \pm 1.33^{c}$ & $71.27 \pm 2.02^{b}$ & $41.55 \pm 0.60^{\mathrm{d}}$ & $78.31 \pm 0.72^{\mathrm{a}}$ \\
\hline \multirow{2}{*}{$\gamma$-amino- $n$-butyric acid } & UFS & $663.83 \pm 3.58^{a}$ & $107.43 \pm 1.07^{\mathrm{d}}$ & $515.72 \pm 1.51^{b}$ & $316.93 \pm 1.37^{c}$ \\
\hline & $\mathrm{CKJ}$ & $853.14 \pm 2.90^{\mathrm{a}}$ & $724.61 \pm 2.61^{b}$ & $611.31 \pm 3.16^{\mathrm{d}}$ & $617.14 \pm 0.45^{c}$ \\
\hline \multirow{2}{*}{ ethanol amine } & UFS & $68.16 \pm 0.87^{a}$ & $36.23 \pm 1.07^{c}$ & $62.03 \pm 1.41^{b}$ & $29.72 \pm 1.34^{\mathrm{d}}$ \\
\hline & $\mathrm{CKJ}$ & $70.16 \pm 1.29^{a, b}$ & $68.33 \pm 1.24^{b}$ & $71.37 \pm 0.99^{a}$ & $52.94 \pm 2.29^{c}$ \\
\hline \multirow{2}{*}{ Total free amino acids } & UFS & $2595.34 \pm 0.82^{c}$ & $2243.26 \pm 1.24^{\mathrm{d}}$ & $3371.00 \pm 2.06^{\mathrm{a}}$ & $3082.94 \pm 2.43^{b}$ \\
\hline & CKJ & $5879.04 \pm 1.27^{\mathrm{c}}$ & $5177.41 \pm 1.23^{d}$ & $6989.48 \pm 1.98^{\mathrm{a}}$ & $6452.05 \pm 2.81^{b}$ \\
\hline
\end{tabular}

1 All values are means of determinations in three independent experiments. Means with different lowercase letters $\left(\mathrm{a}, \mathrm{b}, \mathrm{c}\right.$, and $\left.\mathrm{d}^{\mathrm{d}}\right)$ indicate significant differences of unfermented soybean and cheonggukjang by Duncan's multiple range tests (DMRT) at the $95 \%$ confidence level. ${ }^{2}$ UFS, unfermented soybean. ${ }^{3} \mathrm{CKJ}$, cheonggukjang. 


\section{Materials and Methods}

\subsection{Chemical}

Glacial acetic acid, Folin-Ciocalteu phenol reagent, 2,2-azinobis (3-ethyl-benzothiazoline-6sulfonic acid) diammonium salt (ABTS), potassium persulfate, ferric chloride, sodium acetate, 2,4,6-tripyridyl-s-triazine (TPTZ), rutin, isoflavone aglycones, including daidzein, genistein, and glycitein, were obtained from Sigma-Aldrich Chemical Co. (St. Louis, MO, USA), and three isoflavone glycosides, including genistin, daidzin, and glycitin, were purchased from Indofine (Hillsborough, FL, USA). HPLC-grade $\mathrm{H}_{2} \mathrm{O}$, methanol, and acetonitrile were purchased from Fisher Scientific (Fairlawn, OH, USA). All chemicals were of analytical grade.

\subsection{Soybean Cultivars and Microorganisms}

Four soybeans cultivars (Daewon, Saedanbeck, Aga 3, and Pungsannamul) were collected from the Genetics and Plant Breeding Lab, School of Applied Biosciences. A previously-isolated strain of Bacillus subtilis (KCTC 13241) from traditionally-fermented cheonggukjang [38] was used for the preparation of CKJ. The Bacillus subtilis was maintained in the laboratory on nutrient agar slants. For inoculum preparation, the activated culture was streaked onto a nutrient agar slant and incubated at $37^{\circ} \mathrm{C}$ for $16 \mathrm{~h}$. The cells were harvested in sterile distilled water, and after adjusting to a concentration of $10^{7}-10^{8}$ total cells $\mathrm{mL}^{-1}$, the suspension was used to inoculate cooked soybeans for fermentation.

\subsection{Preparation of Cheonggukjang}

$500 \mathrm{~g}$ of soybeans of each cultivar were sorted, washed, soaked in water for $12 \mathrm{~h}$ at $25^{\circ} \mathrm{C}$, drained, and steam-heated for $30 \mathrm{~min}$ at $121^{\circ} \mathrm{C}$. The cooked mass was cooled to approximately $40{ }^{\circ} \mathrm{C}$, inoculated with a $3 \%(v / w)$ B. subtilis culture medium $\left(10^{7}-10^{8} \mathrm{CFU} / \mathrm{mL}\right)$, and fermented in an incubator for $48 \mathrm{~h}$ at $42{ }^{\circ} \mathrm{C}$ [39].

\subsection{Viable Cell Number and $p H$}

A $1 \mathrm{~g}$ of sample was mixed with $9 \mathrm{~mL} 0.85 \% \mathrm{NaCl}$ solution, and diluted suspensions $(0.1 \mathrm{~mL}$ portions) were spread on a tryptic soy agar (TSA) plate. The plates were incubated at $37^{\circ} \mathrm{C}$ for $24 \mathrm{~h}$, after which colony counts were carried out. A $10 \mathrm{~g}$ portion of the CKJ samples, with different cultivars, was dissolved in $90 \mathrm{~mL}$ of distilled water at room temperature for $1 \mathrm{~h}$ and was then filtered through Whatman No. 4 filter paper (Millipore, Billerica, MA, USA). The filtrate $\mathrm{pH}$ was measured by a $\mathrm{pH}$ meter (PHS-3BW, Bante, Shanghai, China) [14].

\subsection{Sample Extraction}

Extractions were carried out by $\mathrm{Xu}$ and Chang [40] with some modifications. Fermented soybeans $(\mathrm{CKJ})$ underwent freeze-drying and then were finely ground by a grinding machine (Speed Rotor Mill, Model KT-02A, Seishin, Fukuoka, Japan). Unfermented soybeans (UFS) were directly ground without freeze-drying. The ground flour was used for extraction. A $1 \mathrm{~g}$ of sample with $10 \mathrm{~mL}$ of $80 \%$ methanol extraction solvent (triplicate) was incubated at $25^{\circ} \mathrm{C}$ for $24 \mathrm{~h}$. The incubated extracts were centrifuged at $3000 \mathrm{rpm}$ for $15 \mathrm{~min}$. The supernatants were filtered through a $0.45 \mathrm{~mm}$ Minipore PVDF filter (Schleicher \& Schuell, GmbH, Dassel, Germany). The filtrate was used for assays of total phenolic content (TPC) and antioxidant activity.

\subsection{DPPH Radical-Scavenging Activity}

The free radical-scavenging activity of UFS and CKJ was measured following the protocol described by Blois [41] with some modifications. Freshly prepared DPPH solution in methanol $(99.90 \%)$ was used for the experiment. A mixture of equal volumes of methanol-extracted samples and freshly prepared $0.1 \% \mathrm{DPPH}$ solution was left in dark for $30 \mathrm{~min}$. The absorbance was measured 
at $517 \mathrm{~nm}$ using a Multiskan GO Microplate Spectrophotometer (Thermo Fischer Scientific, Vantaa, Finland). An equal proportion of DPPH and methanol was mixed to measure the absorbance of the control. The DPPH radical-scavenging activity was calculated from the absorbance according to the following equation:

$$
\text { DPPH radical-scavenging activity }(\%)=\left[1-\left(\left(\mathrm{S}-\mathrm{S}_{0}\right) / \mathrm{C}\right)\right] \times 100
$$

where $\mathrm{S}=$ absorbance of DPPH and sample, $\mathrm{S}_{0}=$ absorbance of methanol and sample, $\mathrm{C}=$ absorbance of control.

\subsection{ABTS Radical-Scavenging Activity}

A spectrophotometric assay of ABTS radical-scavenging activity was performed as described in our previous study [42]. Briefly, ABTS cation radicals were generated by reacting $7 \mathrm{mM}$ ABTS solution with $140 \mathrm{mM}$ potassium persulfate, which was allowed to stand in the dark at room temperature for $16 \mathrm{~h}$. Before usage, the solution was diluted to achieve an absorbance of $0.7 \pm 0.02$ at $734 \mathrm{~nm}$ with $50 \%$ ethanol. To determine the scavenging activity, the ABTS reagent was mixed with the sample and the absorbance at $734 \mathrm{~nm}$ was measured $3 \mathrm{~min}$ after the initial mixing, using $50 \%$ ethanol as the blank. Ascorbic acid was used as a positive control. The scavenging capability of the ABTS radical was calculated using the following equation:

$$
\text { Inhibition rate }(\%)=(\text { Control O.D } / \text { Sample O.D }) \times 100
$$

\subsection{Superoxide Dismutase (SOD)-Like Activity}

Assessment of SOD-like activity was performed using the method described by Cho et al. [43]. Tris- $\mathrm{HCl}$ buffer ( $50 \mathrm{mM}, 0.3 \mathrm{~mL}$; hydroxymethyl amino-methane, $10 \mathrm{mM}$ EDTA, $\mathrm{pH}$ 8.5) and $0.2 \mathrm{~mL}$ of $7.2 \mathrm{mM}$ pyrogallol were applied to a $0.2 \mathrm{~mL}$ extracted sample and reacted at $25^{\circ} \mathrm{C}$ for $10 \mathrm{~min}$. The reaction was stopped by applying $1 \mathrm{~mL}$ of $1 \mathrm{~N} \mathrm{HCl}$. The amount of pyrogallol oxidised during the reaction was measured at an absorbance at $420 \mathrm{~nm}$. The difference in the absorbance between the experimental group and the control group was recorded as a percentage.

$$
\text { SOD-like activity }(\%)=[(\text { Control }- \text { Sample }) / \text { Control }] \times 100
$$

\subsection{Isoflavone Analysis}

Isoflavone analysis was performed using the method described by Kuan [44], with slight modifications. Briefly, $1 \mathrm{~g}$ of each sample was defatted with $5 \mathrm{~mL}$ hexane and then extracted for $1 \mathrm{~h}$ at room temperature with $5 \mathrm{~mL}$ acetonitrile, $4.5 \mathrm{~mL}$ water, and $0.5 \mathrm{~mL}$ of the internal standard THB $(0.5 \mathrm{mg} / \mathrm{mL})$. After centrifugation at $10,000 \times g$ for $20 \mathrm{~min}$, the supernatant was collected through filter paper No 42 . The extraction solvent was evaporated at $35{ }^{\circ} \mathrm{C}$ to dry. Ten $\mu \mathrm{L}$ of filtrate was injected into an HPLC system equipped with a Symmetry $\mathrm{C} 18$ column after the system had been equilibrated at $30{ }^{\circ} \mathrm{C}$. The UV detector was stabilized with a mobile phase (A: Acetonitrile, B: HPLC water (1\% acetic acid), A: $5 \%$ ( $1 \mathrm{~min}$ ), $5 \rightarrow 35 \%$ ( $50 \mathrm{~min}$ ), $35 \rightarrow 5 \%$ (5 min), $5 \%$ (15 min) at a flow rate of $1.0 \mathrm{~mL} / \mathrm{min}$ ). The effluent was detected at $254 \mathrm{~nm}$. The isoflavones were identified by their retention times of standard addition, and their contents were calculated by comparing their peak areas with those of standards.

\subsection{Total Phenolic Contents (TPC)}

Total phenolic contents were measured by the Folin-Ciocalteu method [45]. Powdered sample $(1 \mathrm{~g})$ was extracted with $10 \mathrm{~mL}$ methanol in a shaking incubator at $25^{\circ} \mathrm{C}$ for $24 \mathrm{~h}$. The mixture was centrifuged at $3000 \mathrm{rpm}$ for $15 \mathrm{~min}$ and the supernatant liquid was filtered through a $0.2 \mu \mathrm{m}$ syringe filter (Water, Milford, MA, USA). Fifty microliters of methanolic extract was added to $1 \mathrm{~mL}$ aqueous 
solution of $2 \%$ sodium carbonate and was left for $3 \mathrm{~min}$. The mixture was mixed with $50 \mu \mathrm{L}$ of $1 \mathrm{~N}$ Folin-Ciocalteu reagent and left in the dark for $30 \mathrm{~min}$ at room temperature. The absorbance was read at $750 \mathrm{~nm}$ using a Multiskan GO Microplate Spectrophotometer (Thermal Fischer Scientific, Vantaa, Finland). The standard calibration curve was plotted using gallic acid. The polyphenol content was expressed as milligram gallic acid equivalent per gram of sample (mg GAE/g).

\subsection{Free Amino Acid Composition}

The free amino acid composition of UFS and CKJ was analysed as described by Waqas [46]. Briefly, approximately $1 \mathrm{~g}$ of ground sample from each was hydrolyzed in $5 \mathrm{~mL}$ of $6 \mathrm{~N} \mathrm{HCl}$ under a vacuum in an ampulla tube for $24 \mathrm{~h}$ at $110{ }^{\circ} \mathrm{C}$. The suspension was then filtered and evaporated under a vacuum. The solid residue was dissolved in $2 \mathrm{~mL}$ of deionized water and evaporated twice. The final residue was dissolved in $10 \mathrm{~mL}$ of $0.01 \mathrm{~N} \mathrm{HCl}$ and filtered through a $0.45 \mu \mathrm{m}$ filter membrane using an automatic amino acid analyser (L-8900 Hitachi, Tokyo, Japan). An amino acid standard mixture solution (type $\mathrm{H}$ ) for automatic amino acid analysis was purchased from Wako Pure Chemical Industries, Ltd. (Osaka, Japan) and used for the accurate analysis of amino acid composition. All of the samples were run in triplicate and expressed in micrograms per gram $(\mu \mathrm{g} / \mathrm{g})$.

\subsection{Statistical Analysis}

Data were subjected to analysis of variance by using SAS version 9.3 (SAS Institute Inc., Cary, NC, USA). The separation of treatment means was conducted using Duncan's multiple range tests (DMRT) at the $95 \%$ confidence level. The results were expressed as the means \pm SD (standard deviation) of three replicates. SigmaPlot was used for graphical presentations.

\section{Conclusions}

Antioxidant activities such as DPPH, ABTS, and SOD-like activity, were markedly increased among all soybean cultivars during $48 \mathrm{~h}$ of fermentation. The isoflavone aglycones were significantly increased while glycosides decreased during fermentation. These changes have been documented for the first time for the microorganism Bacillus subtilis (KCTC 13241). These developments might be due to the $\beta$-glucosidase produced by $B$. subtilis. This research also suggested that the high antioxidant activity of CKJ might be related to the higher isoflavone aglycone levels and higher total phenolic contents that increase during fermentation. Among all the studied soybean cultivars, CKJ prepared from Aga 3 proved to be the most markedly significant in antioxidant activity, total phenolic content, and isoflavones levels, as well as free amino acid composition. Additionally, soybean cultivar Aga 3 could be recommended for the commercial production of fermented soybean. Furthermore, all other cultivars showed notable nutritional and biological contents, such as isoflavones, phenolic contents, antioxidants, and free amino acids. The difference between UFS and CKJ might be due to the fermentation period ( $48 \mathrm{~h}$ ) and differences among cultivars might be due to genotype, crop location, crop year, storage period, climatic conditions, seed size, and colour. Moreover, further research is essential for examining the effects of isoflavones, determination of the molecular mechanisms responsible for the antioxidant activitie, and amino acid profile modification for health benefits and pharmaceutical drugs.

Acknowledgments: The authors would like to thank Byung Oh Kim for his assistance during this research.

Author Contributions: M.W.A., I.-D.K., and D.-H.S. designed the study and interpreted the results. M.W.A., S.B., B.A., R.S., and J.R.K. performed the experiments and analysed the results. M.T.S., R.B.S.N., and D.-H.S. drafted the manuscript.

Conflicts of Interest: The authors declare no conflict of interest. 


\section{References}

1. García, M.C.; Puchalska, P.; Esteve, C.; Marina, M.L. Vegetable foods: A cheap source of proteins and peptides with antihypertensive, antioxidant, and other less occurrence bioactivities. Talanta 2013, 106, 328-349. [CrossRef] [PubMed]

2. Kim, E.H.; Kim, S.H.; Chung, J.I.; Chi, H.Y.; Kim, J.A.; Chung, I.M. Analysis of phenolic compounds and isoflavones in soybean seeds (Glycine max (L.) Merill) and sprouts grown under different conditions. Eur. Food Res. Technol. 2006, 222, 201-208. [CrossRef]

3. Coward, L.; Barnes, N.C.; Setchell, K.D.; Barnes, S. Genistein, Daidzein, and Their \& Glycoside Conjugates: Antitumor Isoflavones in Soybean Foods from American and Asian Diets. J. Agric. Food Chem. 1993, 41, 1961-1967.

4. Robert, L.; Walter, J. Compositional changes in trypsin inhibitors, phytic acid, saponins and isoflavones related to soybean processing. J. Nutr. 1995, 125, S581.

5. Kumar, M.; Nagpal, R.; Kumar, R.; Hemalatha, R.; Verma, V.; Kumar, A.; Chakraborty, C.; Singh, B.; Marotta, F.; Jain, S.; et al. Cholesterol-lowering probiotics as potential biotherapeutics for metabolic diseases. Exp. Diabetes Res. 2012, 2012. [CrossRef] [PubMed]

6. Hu, Y.; Ge, C.; Yuan, W.; Zhu, R.; Zhang, W.; Du, L.; Xue, J. Characterization of fermented black soybean natto inoculated with Bacillus natto during fermentation. J. Sci. Food Agric. 2010, 1194-1202. [CrossRef] [PubMed]

7. Sheih, I.C.; Wu, H.Y.; Lai, Y.J.; Lin, C.F. Preparation of high free radical scavenging tempeh by a newly isolated Rhizopus sp. R-69 from Indonesia. Food Sci. Agric. Chem. 2000, 2, 35-40.

8. Yen, G.; Chang, Y.; Su, S. Antioxidant activity and active compounds of rice koji fermented with Aspergillus candidus. Food Chem. 2003, 83, 49-54. [CrossRef]

9. Cao, X.; Wang, A.H.; Jiao, R.Z.; Wang, C.L.; Mao, D.Z.; Yan, L.; Zeng, B. Surfactin Induces Apoptosis and G 2/M Arrest in Human Breast Cancer MCF-7 Cells Through Cell Cycle Factor Regulation. Cell Biochem. Biophys. 2009, 163-171. [CrossRef] [PubMed]

10. Yee, N.; Jeong, E.; Young, D.; Pyo, H. Antioxidant and antigenotoxic activities of Korean fermented soybean. Food Chem. Toxicol. 2008, 46, 1184-1189. [CrossRef]

11. Byun, M.; Son, J.; Yook, H.; Jo, C.; Kim, D. Effect of gamma irradiation on the physiological activity of Korean soybean fermented foods, Chungkookjang and Doenjang. Radiat. Phys. Chem. 2002, 64, 245-248. [CrossRef]

12. Omura, K.; Hitosugi, M.; Zhu, X.; Ikeda, M.; Maeda, H. A Newly Derived Protein from Bacillus subtilis natto with Both Antithrombotic and Fibrinolytic Effects. J. Pharmacol. Sci. 2005, 251, 247-251. [CrossRef]

13. D'Adamo, C.R.; Sahin, A. Soy foods and supplementation: A review of commonly perceived health benefits and risks. Altern. Ther. Health Med. 2014, 20 (Suppl. 1), 39-51. [CrossRef] [PubMed]

14. Cho, K.M.; Lee, J.H.; Yun, H.D.; Ahn, B.Y.; Kim, H.; Seo, W.T. Changes of phytochemical constituents (isoflavones, flavanols, and phenolic acids) during cheonggukjang soybeans fermentation using potential probiotics Bacillus subtilis CS90. J. Food Compos. Anal. 2011, 24, 402-410. [CrossRef]

15. Cho, K.M.; Hong, S.Y.; Math, R.K.; Lee, J.H.; Kambiranda, D.M.; Kim, J.M.; Islam, S.M.A.; Yun, M.G.; Cho, J.J.; Lim, W.J.; et al. Biotransformation of phenolics (isoflavones, flavanols and phenolic acids) during the fermentation of cheonggukjang by Bacillus pumilus HY1. Food Chem. 2009, 114, 413-419. [CrossRef]

16. Kim, M.; Han, S.; Ko, J.; Kim, Y. Degradation Characteristics of Proteins in Cheonggukjang (Fermented Unsalted Soybean Paste) Prepared with Various Soybean Cultivars. Food Sci. Biotechnol. 2012, 21, 9-18. [CrossRef]

17. Shon, M.; Kim, T.; Sung, N. Antioxidants and free radical scavenging activity of Phellinus baumii (Phellinus of Hymenochaetaceae) extracts. Food Chem. 2003, 82, 593-597. [CrossRef]

18. Haque, A.; Hwang, C.E.; Lee, H.Y.; Ahn, M.J.; Sin, E. Comparison of Isoflavone Contents and Antioxidant Effect in Cheonggukjang with Black Soybean Cultivars by Bacillus subtilis CSY191. Korean J. Environ. Agric. 2016, 35, 62-71. [CrossRef]

19. Almeida, M.M.B.; de Sousa, P.H.M.; Arriaga, Â.M.C.; do Prado, G.M.; de Carvalho Magalhães, C.E.; Maia, G.A.; de Lemos, T.L.G. Bioactive compounds and antioxidant activity of fresh exotic fruits from northeastern Brazil. Food Res. Int. 2011, 44, 2155-2159. [CrossRef]

20. Morales, G.; Paredes, A. Antioxidant activities of Lampaya medicinalis extracts and their main chemical constituents. BMC Complement. Altern. Med. 2014, 1-12. [CrossRef] [PubMed] 
21. Cho, M.J.; Lee, J.Y.; Kim, J.H. Microbial and Physiochemical Properties of Cheonggukjang Fermented Using Bacillus Strains with Antibacterial or Antifungal Activities. Food Sci. Biotechnol. 2014, 23, 1525-1532. [CrossRef]

22. Hwang, C.E.; Seo, W.T.; Cho, K.M. Enhanced Antioxidant Effect of Black Soybean by Cheonggukjang with Potential Probiotic Bacillus subtilis CSY191. Korean J. Environ. Agric. 2013, 49, 391-397. [CrossRef]

23. Oh, H.J.; Kim, C.S. Antioxidant and Nitrite Scavenging Ability of Fermented Soybean Foods (Chungkukjang, Doenjang). J. Korean Soc. Food Sci. Nutr. 2007, 36, 1503-1510. [CrossRef]

24. Choi, U.; Kim, M.; Lee, N.H.; Jeong, Y.; Kwon, O.; Kim, Y.; Hwang, Y. The Characteristics of Cheonggukjang, a Fermented Soybean Product, by the Degree of Germination of Raw Soybeans. Food Sci. Biotechnol. 2007, 16, 734-739.

25. Wojdyło, A.; Oszmiański, J.; Czemerys, R. Antioxidant activity and phenolic compounds in 32 selected herbs. J. Food Chem. 2007, 105, 940-949. [CrossRef]

26. Shin, E.C.; Lee, J.H.; Hwang, C.E.; Lee, B.W.; Kim, H.T.; Ko, J.M.; Baek, I.Y.; Shin, J.H.; Nam, S.H.; Seo, W.T.; et al. Enhancement of total phenolic and isoflavone-aglycone contents and antioxidant activities during Cheonggukjang fermentation of brown soybeans by the potential probiotic Bacillus subtilis CSY191. Food Sci. Biotechnol. 2014, 23, 531-538. [CrossRef]

27. Vaya, J.; Tamir, S. The Relation Between the Chemical Structure of Flavonoids and Their Estrogen-Like Activities. Curr. Med. Chem. 2004, 11, 1333-1343. [CrossRef] [PubMed]

28. Prabhakaran, M.P.; Perera, C.O.; Valiyaveettil, S. Effect of different coagulants on the isoflavone levels and physical properties of prepared firm tofu. J. Food Chem. 2006, 99, 492-499. [CrossRef]

29. Yang, S.O.; Chang, P.S.; Lee, J.H. Isoflavone Distribution and $\beta$-Glucosidase Activity in Cheonggukjang, a Traditional Korean Whole Soybean-Fermented Food. Food Sci. Biotechnol. 2006, 15, 96-101.

30. Velioglu, Y.S.; Mazza, G.; Gao, L.; Oomah, B.D. Antioxidant Activity and Total Phenolics in Selected Fruits, Vegetables, and Grain Products. J. Agric. Food Chem. 1998, 46, 4113-4117. [CrossRef]

31. Mayer, R.R.; Cherry, J.H.; Rhodes, D. Effects of Heat Shock on Amino Acid Metabolism of Cowpea Cells. Plant Physiol. 1990, 94, 796-810. [CrossRef] [PubMed]

32. Gerich, J.E.; Meyer, C.; Woerle, H.J.; Stumvoll, M. Renal Gluconeogenesis Its importance in human glucose homeostasis. Diabetes Care 2001, 24, 382-391. [CrossRef] [PubMed]

33. Ruth, M.R.; Field, C.J. The immune modifying effects of amino acids on gut-associated lymphoid tissue. J. Anim. Sci. Biotechnol. 2013. [CrossRef] [PubMed]

34. Genene, A.; Winans, S. Distribution of methionine and leucine enkephalin neurons within the social behavior circuitry of the male Syrian hamster brain. Brain Res. 2004, 1030, $28-48$.

35. Chen, P.E.; Geballe, M.T.; Stansfeld, P.J.; Johnston, A.R.; Yuan, H.; Jacob, A.L.; Snyder, J.P.; Traynelis, S.F.; Wyllie, D.J.A. Structural Features of the Glutamate Binding Site in Recombinant NR1/NR2A N-MethylD-aspartate Receptors Determined by Site-Directed Mutagenesis and Molecular Modeling. Mol. Pharmacol. 2005, 67, 1470-1484. [CrossRef] [PubMed]

36. Vaquero, J.; Butterworth, R.F. The brain glutamate system in liver failure. J. Neurochem. 2006, 661-669. [CrossRef] [PubMed]

37. Park, M.K.; Cho, I.H.; Lee, S.; Choi, H.K.; Kwon, D.Y.; Kim, Y.S. Metabolite profiling of Cheonggukjang, a fermented soybean paste, during fermentation by gas chromatography-mass spectrometry and principal component analysis. Food Chem. 2010, 122, 1313-1319. [CrossRef]

38. Lee, N.K.; Park, J.W.; Cho, I.J.; Kim, B.; Kwon, K.; Hahm, Y.T. Isolation of Bacillus spp. from Cheonggukjang and Its Antagonistic Effect against Bacillus cereus. Korean J. Food Sci. Technol. 2008, 40, 669-673.

39. Kim, M.-H.; Kim, S.-Y.; Ko, J.-M.; Jeong, D.-Y.; Kim, Y.-S. Biological activities of cheonggukjang prepared with several soybean cultivars. Food Sci. Biotechnol. 2012, 21, 475-483. [CrossRef]

40. Xu, B.J.; Chang, S.K.C. A Comparative Study on Phenolic Profiles and Antioxidant Activities of Legumes as Affected by Extraction Solvents. J. Food Sci. 2005. [CrossRef] [PubMed]

41. Blois, M.S. Antioxidant Determinations by the Use of a Stable Free Radical. Nature 1958, 181, 1199-1200. [CrossRef]

42. Bilal, S.; Khan, A.L.; Waqas, M.; Shahzad, R.; Kim, I.D.; Lee, I.J.; Shin, D.H. Biochemical constituents and in vitro antioxidant and anticholinesterase potential of seeds from Native Korean Persimmon Genotypes. Molecules 2016, 21, 893. [CrossRef] [PubMed] 
43. Cho, K.M.; Seo, W.T. Bacterial Diversity in a Korean Traditional Soybean Fermented Foods (Doenjang and Ganjang) by 16S rRNA Gene Sequence Analysis. Food Sci. Biotechnol. 2007, 16, 320.

44. Kuan, S. A Simplified HPLC Method for the Determination of Phytoestrogens in Soybean and Its Processed Products. J. Agric. Food Chem. 1990, 35, 185-190.

45. Dewanto, V.; Wu, X.; Adom, K.K.; Liu, R.H. Thermal Processing Enhances the Nutritional Value of Tomatoes by Increasing Total Antioxidant Activity. J. Agric. Food Chem. 2002, 50, 3010-3014. [CrossRef] [PubMed]

46. Waqas, M.; Shahzad, R.; Latif, A.; Asaf, S.; Kim, Y.; Kang, S.; Bilal, S.; Hamayun, M.; Lee, I. Plant Physiology and Biochemistry Salvaging effect of triacontanol on plant growth, thermotolerance, macro-nutrient content, amino acid concentration and modulation of defense hormonal levels under heat stress. Plant Physiol. Biochem. 2016, 99, 118-125. [CrossRef] [PubMed]

Sample Availability: Samples of the compounds are available from the authors.

(C) 2017 by the authors. Licensee MDPI, Basel, Switzerland. This article is an open access article distributed under the terms and conditions of the Creative Commons Attribution (CC BY) license (http:/ / creativecommons.org/licenses/by/4.0/). 